\title{
Inclusive Education as Socio-Pedagogical Factor in Modernization of High Education
}

\author{
Marina A. Fedorova ${ }^{*}$, Kseniya S. Nelepko, and Diana A. Fandeyeva \\ Orel State University named after I.S. Turgenev, 302026 Orel, Russian Federation
}

\begin{abstract}
The article deals with various aspects of inclusive education in Russia. Characteristics of children with special adaptive abilities are given, that is, individuals whose health or development impedes self-care, independent movement, orientation, communication, control of their behavior, mastering educational programs, work activity, that is, adaptation in society and socialization without specially created conditions. Factors and tendencies successfully realized in professional training of specialists and education of children with various possibilities of adaptation and socialization are revealed, administrative reasons, psycho-pedagogical and socio-economic nature, preventing the full integration of inclusive education in educational institutions of the Russian Federation are determined. Attention is focused on the need to modernize the professional and pedagogical training of specialists in the training of persons with HIA. Theoretical and practical substantiations are proposed as the directions of this restructuring, which ensure the theoretical and practical readiness of the teacher for professional activity with children with special adaptive abilities.
\end{abstract}

\section{Introduction}

The global trends of a growing number of children with special adaptive abilities (disabled children) dictate the need to create beneficial environment for their adaptation in the society. Fundamental statistical investigations indicate that there is a number of difficulties and problems associated with education and integration of that type of children in the educational environment. There are successful educational practices for disabled children all over the world and locally. Inclusive education is being widely applied for teaching disabled children in the same group of children with normal abilities. The experience of inclusive education in the leading European and American countries and Israel is especially noteworthy as it demonstrates the prospects for creating beneficial conditions for that type of children.

Handicapped children refer to a special category of children whose health and development prevent them from self-care, independent moving, orientation, communication, behaviour control, learning, work, i.e. from being adapted in the society and socialised unless special environment is created. Those are children under 18 years old with various deviations of psychic, physical or social nature contributing to their general development disorder and preventing them from their full integration into the society. This term usually implies children with hearing or visual or speech disorder, locomotor apparatus disorder, with mental deficiency, mental retardation, behaviour and communication disorder, complex physical development disorder, and multiple disabilities (blind deaf-mute, deaf or mute children with mental deficiency).

\section{Results and Discussion}

In 2012, the Russian Federation ratified the Convention on the Rights of Physically Challenged People (Federal Law No. 46-FL of 03.05.2012), according to which disability is an evolving concept. Disability is the result of interaction that occurs between people with disabilities and barriers in the environment and relationships in society that interfere with their full and effective participation in the life of society [2].

The concept of "children with health limitations" has been used in pedagogical literature for a long time, but in recent years the essence of this notion has been actively rethought. Initially, "the inclusion" implied reforming and rearrangement of schoolrooms based on the needs of all children. Later it implied personnel training and awareness of the specifics related to various categories of "special" children. "Health Limitations" begin to be viewed not so much as the physiological or mental deficiency of the individual, but rather as the unformed nature of the external conditions (material, sociocultural, etc.), which should ensure that the children of this group have the opportunity to live a full life. Ensuring the accessibility of education for all categories of the child population is one of the paramount tasks of inclusive education.

\footnotetext{
* Corresponding author: 09011975m@ gmail.com
} 
These days, there are a lot of debates about the importance of introducing inclusive education. What is inclusive education? Inclusive education presupposes combined education and upbringing of children with disabilities with children who have no restrictions.

Such education includes not only the organization of joint training sessions, but also joint leisure, various types of additional education, such as educational clubs and extra-curricular activities. The introduction of inclusive education is a complex process as it affects various social groups: children with health limitations, as well as children without developmental disabilities, parents, educators of mass and special schools, specialists in various fields.

A theory of genesis of high psychological functions developed by L.S. Vygotski [1] is the psychological basis for the inclusion as part of the educational system in Russia. According to I.V. Zhulanova, “... ultimately important role of the people's interaction that gives rise to the conditions for learning a new cultural form - the interaction when applied to the early ontogenesis is called an interform and is the basis of interiorisation." [4]. The author introduces the concept "Inclusive Oriented Education" for the first time. This education is aimed at co-education and upbringing of children with normal development and various abnormalities.

The development of the Russian state, economy, politics, society and culture, educational theory and practice creates prerequisites for inclusive education. Integrated and inclusive education for children with somatic disorders are gaining ground in Russia. The formation of socially oriented, pragmatic, independent personality capable to develop and cooperate with others regardless of age, sex, nationality, religion, diseases has become the key note of inclusion in Russia.

N.V. Borisova, S.A. Prushinsky, considering the reasons for the development of inclusive education as a world trend, note that the inclusive approach to education was affirmed in connection with the fact that in modern society a "medical" model that defines disability as a violation of health and limits support for people with a disability of social protection of the sick and incapable, gives way to the "social" model, which states:

- the cause of disability is not in the disease itself;

- the cause of disability is the existing physical ("architectural") and organizational ("relative") barriers, stereotypes and prejudices existing in the society "[4].

There is an understanding that a "barrier-free" educational environment is an environment where a child with health limitations does not experience difficulties, has all the conditions for self-realization, self-education, moral and mental development, physical growth and social adaptation.

Children with disabilities, in most cases, would like to study not in special educational institutions, but in mass general schools, be proper citizens of society, interact with the outside world in the same way as healthy children do. When they are deprived of the opportunity to grow and develop "like everyone else", it causes a deep psychological trauma, changes their attitude towards humanity, forms a sense of uselessness and loneliness. Combined training helps develop strong, unselfish friendship, teach assistance and respect, prevent the emergence of stereotypes and prejudices. Allowing children with health limitations to study with children without any deviation means giving them a chance to believe in themselves and their strength. Thus, they will be able to understand that not only parents are ready to help them to deal with difficulties, but also the state, their peers, and teachers.

Today inclusive education has a great potential. It makes it possible to involve children with special educational needs into different kinds of physical, aesthetic, cultural, social activity, thus helping in realization of social contacts, cooperation of children who have normal progression with children who have developmental disabilities.

The research has demonstrated that the reasons why inclusive education cannot be currently integrated into the regional educational programme of Orel region and Russia on the whole to the full are the following:

First and foremost, these are the issues of governance character:

- the absence of a good management tool for proper social adaptation in educational system;

- the unwillingness of administration of educational institutions to involve children with particular adaptive needs into the groups of children with normal progression;

- the absence of a flexible system of variative education in Russia.

The issues of pedagogical character:

- poor inclusive resources in a process of social adaptation;

- unsatisfactory level of pedagogical staff training in institutes of higher education, level of schools, of preprimary schools and institutions of complementary education.

The psycho-pedagogical reasons to which many scholars attribute:

- the unwillingness of other children who study in inclusive educational institutions and the unwillingness of their parents to see difficulties, needs and wishes of a child with peculiar adaptive needs;

- misunderstanding of the society and its unpreparedness to integrate a child with special learning needs;

- the lack of special training for teachers in the subject area to work with children with HIA

There are also some reasons of social and economic character:

- a family of a disabled child does not have enough money for good education of that child;

- an educational institution doesn't have enough money for re-equipment of classes and retraining of stuff for work with children who have special learning needs.

As for the problems of socio-economic and managerial nature, their solution is a task of the government and the educational community, which are ready to solve them. This is proved by the events, which are conducted in the process of improving regulatory 
documents of inclusive education. On the one hand, they are Federal Laws in the Russian Federation, in which there are not only the concept of inclusive education, but also regulated organization of education for students with disabilities. On the other hand, it is an introduction of Federal State Educational Standard (FSES), according to which basic educational programs' implementation of general education can be organized together with other students and in individual classrooms, groups or individual organizations. These measures are gradually gaining traction. The monitoring of educational institutions in Russia demonstrates that the inclusive education is based on the principle of several categories of children staying in the same room (nursery group, school classroom, university lecture room, further educational institution). Disabled children stay there full day or part time doing their individual plan under supervision of a trained teacher. For most Russian educational institutions the inclusion implies orientation to the training, upbringing and development of all students based on their personal traits.

It should be noted that the basics of social adaptation of disabled children to the inclusive school's environment are region-specific in terms of social and economic development of the region, cultural traditions of the area, psychological preparedness of the people to welcome a "special" child, specifics of the schools, professional skills of the teachers qualified for inclusive schools, purpose-oriented work of mass media to explain to the people of the region the benefits of inclusive education both for the children with special educational needs and children with normal development, availability and activities of public organisations.

The aforementioned determines the necessity of the reorganization of professional- pedagogical education, which is aimed at training a competent teacher who meets the needs of modern society, the teacher who is willing and able to work in the inclusive educational environment. We are of the opinion that modernization of professional-pedagogical training should go in several directions.

First, it is a theoretical course where the introduction of special theoretical topics (modules) in the content of educational disciplines that is studied during the psychopedagogical and medical training or individual courses that provide the readiness of future teachers to work in inclusive educational environment is expedient.

Second, it is a practical course in which, on the one hand, it is necessary to ensure the future teachers' psychological readiness to work with disabled children, for example, by carrying out different psychological trainings, and, on the other hand, it is a pedagogical practice in which the student, the future teacher, acquire skills and habits to interact with disabled children simultaneously.

Since the professional activity of inclusive teachers goes beyond the traditional teacher's activities and it interacts and interlinks closely with different types of socio-educational, rehabilitative, consultative-diagnostic, psychotherapeutic, correctional and other types of "noneducational" work.
Thus, the professional education of a modern teacher is a "multifaceted" training. On the one hand, it is the training of a subject teacher. On the other hand, it is the training of a tutor that accompanies disabled children throughout the educational process. He is familiar with their peculiarities of development and he contacts with parents. $\mathrm{He}$ also provides disabled children with necessary technical assistance during the educational process together with children without special health problems in general education schools.

A specialist who works with physically challenged children must have a higher education qualification, good academic training and necessary practical experience to work with children aged under 18 who have certain mental, physical, sensory or psychical disorders showing that a child has some adaptive needs.

Nowadays for successful and effective operations with physically challenged children, experts from various disciplines adopt a more integrated approach to help them.

Modern integration of physically challenged children into the society has a new philosophical basis with equal civilian rights and reformation of the education system. One of the major issues is good professional training of specialists in institutes of higher education for work with such physically challenged children.

Table 1. Information on the number of students with HIA in Orel State University named after I.S. Turgenev for the 20172018 academic year.

\begin{tabular}{|c|l|c|}
\hline № & \multicolumn{1}{|c|}{ Name of the structural unit } & $\begin{array}{c}\text { Number } \\
\text { of people } \\
\text { with HIA }\end{array}$ \\
\hline 1. & $\begin{array}{l}\text { Institute of Instrument Making, Automation } \\
\text { and Information Technologies }\end{array}$ & 7 \\
\hline 2. & $\begin{array}{l}\text { Polytechnic Institute named after N.N. } \\
\text { Polikarpova }\end{array}$ & 6 \\
\hline 3. & Institute of Economics and Management & 6 \\
\hline 4. & Law Institute & 4 \\
\hline 5. & Faculty of Natural Sciences & 12 \\
\hline 6. & University of Foreign languages & 4 \\
\hline 7. & $\begin{array}{l}\text { Faculty of Technology, Entrepreneurship } \\
\text { and Service }\end{array}$ & 4 \\
\hline 8. & Institute of Philology & 1 \\
\hline 9. & Institute of Pedagogy and Psychology & 7 \\
\hline 10. & Faculty of Philosophy & 1 \\
\hline 11. & Social Faculty & 7 \\
\hline 12. & History Faculty & 5 \\
\hline 13. & Faculty of Physics and Mathematics & 8 \\
\hline 14. & Medical Institute & 21 \\
\hline 15. & Graphic Arts Faculty & 2 \\
\hline 16. & Architectural and Construction Institute & 4 \\
\hline 17. & Faculty of Secondary Vocational Education & 7 \\
\hline 18. & Postgraduate study & 2 \\
\hline 19. & Part-time Education & 17 \\
\hline &
\end{tabular}

Today mainly teacher's training colleges prepare specialists for work with children who have special adaptive needs. These specialists are social care teachers, psychologists, caseworkers, teachers of correctional institutions of education and etc. At the same time, totally unprepared specialists for work with such physically challenged children in inclusive educational 
institutions can be the pedagogues who have received their education beyond following professions: teachers of initial classes, teachers of the Russian language and Literature, teachers of Maths, Chemistry, History, Geography, life safety teachers, drawing teachers and others.

According to figures of recent survey, exactly these teachers have the most serious difficulties with work with such children and seek the assistance of competent specialists.

\section{Conclusion}

At present time, there is a real necessity of training future specialists of various disciplines for work with physically challenged children in inclusive educational institutions. There is need for invention of new train technologies and development of a first-rate vision which is quite acceptable at the modern phase of the world`s and Russian`s education system development. The analysis of present preparation of future specialists showed the necessity of understanding of the essence and the peculiarities of the usage of such first-rate vision.

Thus, inclusive oriented education is not only sociopedagogical and public-economic factor of current education's modernization. Moreover, the system of inclusive education in Russia has just started out. Both the teachers and the parents of disabled children have significant problems. Nevertheless, there are positive trends for various activities with disabled children.

\section{References}

1. L.S. Vygotskiy, Problems of psyche development (M.: Pedagogica 3, 1983)

2. N.S. Groznaya, Down Syndrome XXI century 1, 3441 (2011)

3. I.V. Zhulanova, Naukovedenie 6, 2013

4. L.I, Lebedeva, E.V Ivanova, School technologies. 5, 116-120 (2002)

5. N.N. Malofeev, Almanac of the institute of corrective pedagogy PAO 1 (2000)

6. T.V Timohina, Innovations in Education 2, 100-110 (2016)

7. A.Ya. Chigrina, Inclusive education of children with serious physical handicaps as a factor of their social integration. Dissertation for sociology (Nizhniy Novgorod, 2011)

8. N.D. Smatko, Scientific and instructional journal. Institute of corrective pedagogy Russian Academy of Education, 94 (2007) 